\title{
Blood Levels of Resistin, Glycemic Indices and Lipid Profile in Women with Type 2 Diabetes
}

\author{
Asghar Tofighi' ${ }^{1}$, Zahra Samadian' ${ }^{1}$ and Alireza Mahdizadeh ${ }^{2 *}$
}

${ }^{1}$ Exercise Physiology, Physical Education and Sports Science, University of Urmia, Urmia, Iran

${ }^{2}$ Department of Internal Diseases, University of Medical Sciences, Urmia, Iran

\begin{abstract}
We aimed to compare the changes in PRL with glycemic indices and lipid profile and also to investigate the relationship of insulin resistance (IR) with PRL in obese postmenopausal women with diabetes mellitus type 2 (DMT2) following 12-week aerobic, resistance and combined exercises, while our inclusion and exclusion criteria and also design exercise protocol differ from other studies in this field. In a quasi-experimental study for 12 weeks, 40 women with DMT2 were randomly selected by availability and purposive sampling and divided into four equal groups of aerobic training, resistance, combined and control group. Aerobic group accomplished aerobic exercise (AEX), 3x/week, for 20-50 minutes at 50-70\% of maximum heart rate. Resistance group received resistance exercise (REX), $3 \mathrm{x} /$ week in three sets of 10 repetitions with $40-60 \%$ of one repetition maximum. The program in combined group consisted of a combination of AEX and REX with the same intensity and duration (included 2 sessions of AEX and 1 session of REX per week. But fortnightly, the numbers of these sessions were changed with each other). The control group was without exercise program. Blood samples for determination of PRL, lipid profile and glycemic indices in pre-and post-tests were collected. HOMA-IR equation was used to calculate insulin resistance. Statistical analysis was performed using SPSS software version 21. According to our finding; the effect of AEX and combined exercises was more than control group on the increasing PRL. The result of AEX in weight loss was more than REX however, the outcome of REX in insulin and IR reducing; also TC declining was more than the AEX. While the effect of combined group in decreasing body fat percent was more than AEX group, but the consequence of AEX was more than the combined group for reducing waist-to-hip ratio (WHR). The effect of the combined group in reducing low density lipoprotein (LDL) was more than the REX group. Also, weight, fasting blood glucose, insulin, triglycerides, LDL, glycosylated hemoglobin A1c and WHR were the predictors of IR. It seems that, during the study period, all three types of exercises through different mechanisms had valuable effects on glycemic indices and lipid profile in DMT2 patients. Also due to the increase in PRL and non-significant correlation with IR; it is doubtful that resistin be as a factor in the incidence of DMT2.
\end{abstract}

Keywords: Exercise; Resistin; Lipid profile; Glycemic indices; Women; Diabetes mellitus type 2

\section{Introduction}

Currently, one of health problem is diabetes mellitus type 2 (DMT2) that characterized by hyperglycemia. It can be a result from impaired insulin secretion, insulin resistance or combination of them [1]. Waistline adipose tissue (central obesity) is one of risk factors for DMT2, especially in postmenopausal women $[2,3]$. Since adipose tissue secretes adipocytokines which affect metabolic status [4,5], there are several discussion about relationship between central obesity and DMT2 as metabolic disorders of carbohydrate metabolism [4,6-9].

Resistin is one of adipocytokines with a molecular weight of 12.5 $\mathrm{KD}$ [10]. In addition to adipose tissue, high levels of resistin exist in monocytes, macrophages, and spleen and bone marrow cells [11]. Several studies have been shown that, resistin plays a role in the development of insulin resistance (IR) $[10,12,13]$. Zhou et al. showed; resistin impairs glucose tolerance by lowering mRNA levels of IRS-2 (insulin receptor substrate 2) and stimulating SOCS-3 (inhibitor of cytokine signaling 3) expression [14]. On the other hand, Utzschneider et al. studied on the relationship between resistin and insulin sensitivity, body fat distribution and the metabolic syndrome in humans. They reported that association of resistin with body fat is inadequate, and its intermediary role is questionable for IR or metabolic disorder in individuals [15]. While resistin was first described as a factor contributing to the development of IR and DMT2 [13], argument continues about its exact role in obesity, insulin sensitivity and the development of DMT2 [16].
Exercise is a non-pharmacologic treatment for DMT2 [17]. Studies have shown that aerobic and resistance exercises can induce metabolic adaptations that improve insulin sensitivity [18-20]. Consequently it seems that, the combined exercises (combination of endurance and resistance training) can have multiple effects of both types of exercises [21]. However, there are controversial studies about the effect of different types of exercises on plasma resistin level (PRL), IR factors and their relationship. According to study from Giannopoulou et al. no change were observed in PRL and reduction in IR after 14 weeks of aerobic exercises (AEX) [22]. In contrast, Jones et al. showed a significant reduction in PRL but without significant change in IR in obese children, followed by 8 months of AEX [23]. Also in another study, PRL reduction was observed after 16 weeks of resistance training (REX) [24]. Unlike this study, one research revealed; no change was observed in PRL and IR after 12 weeks of REX [25].

*Corresponding author: Alireza Mahdizadeh, Assistant Professor, Department of Internal Diseases, University of Medical Sciences, Urmia, Iran, Tel: 8253426543; E-mail: alireza.mahdizadeh1@gmail.com

Received August 10, 2016; Accepted September 13, 2016; Published September 12,2016

Citation: Tofighi A, Samadian Z, Mahdizadeh A (2016) Blood Levels of Resistin, Glycemic Indices and Lipid Profile in Women with Type 2 Diabetes. J Diabetes Metab 7: 702. doi: 10.4172/2155-6156.1000702

Copyright: $\odot 2016$ Tofighi A, et al. This is an open-access article distributed under the terms of the Creative Commons Attribution License, which permits unrestricted use, distribution, and reproduction in any medium, provided the original author and source are credited. 
Excess body fat due to sedentary lifestyles more commonly seen in postmenopausal women, this issue led to an increase in the incidence of diabetes in these women [26]. Since regular exercise is recognized to decrease risk for metabolic disorder via several mechanisms [27] this question are arises that; whether implementation of exercise as a therapeutic strategy, can lead to changes in IR by changing the PRL among patients with DMT2?

Therefore, this study aimed to compare changes in PRL, lipid profile and glycemic indices in obese postmenopausal women with DMT2 followed by 12 weeks of aerobic, resistance and combined exercises. Also we intended to provide regression models for insulin resistance in both pre-and post-test conditions.

\section{Materials and Methods}

\section{Study design and sampling method}

This quasi-experimental study with pre- and post-test design was achieved by purposive sampling method based on availability among the study population.

\section{Study population and setting}

The study population included 40 obese postmenopausal women with DMT2 who referred to the endocrinology and metabolism clinic of Imam Khomeini Hospital, Urmia city- the capital of West Azarbayjan province, located in north-western of Iran. Participants were randomly divided into four equal groups of aerobic training, resistance, combined and control group. Inclusion criteria included; having fasting blood glucose (FBG) more than $126 \mathrm{mg} / \mathrm{dl}$ - according to World Health Organization (WHO) criteria- [28] for at least six months, lack of a history of physical activity, weight fluctuations amounting to $10 \%$ of own weight. It should be noted that, all subjects were taking metformin (500 mg), 2 glibenclamide $(5 \mathrm{mg})$ and 1 atorvastatin $(20 \mathrm{mg})$ daily three times a day during the last 6 months and during the study. Exclusion criteria included insulin therapy, acute or chronic disease (high blood pressure, nephropathy, retinopathy, cardio-vascular, kidney, liver, thyroid and orthopedic disease) and any intervention that affecting the experimental results.

\section{Experimental procedures}

For all participants were explained that our aim is not weight loss due to a regimen. So they should not alter their diet as directed by their physician. It was emphasized that we attempt about the effects of exercises. The study continued with the following phases:

Screening sessions: At the start, informed consent was obtained. Then all subjects complete Physical Activity Readiness Questionnaire (PAR-Q) which is a safe preliminary screening of candidates for exercise testing and prescription [29]. Afterward, blood glucose, blood pressure, resting heart rate and medical history were assessed and recorded. For each participant, the systolic and diastolic blood pressure was taken using OMRON M3 Intellisense upper arm blood pressure monitor (HEM-70 51-E) made in China, after at least 10-15 minutes of rest. If the pre-exercise blood pressure was less than 140/90 $\mathrm{mm} \mathrm{hg}$, subject could participate in training exercise. If the preexercise blood pressure was greater than or equal to $140 / 90 \mathrm{~mm} \mathrm{hg}$, she was asked for 10 minute break and re-evaluate their blood pressure. With an uncontrolled hypertension, intervention had not been done on that day. If the subjects had low blood glucose levels (less than $100 \mathrm{mg} / \mathrm{dl}$ ), they had to consume the syrup contains about 15 grams of carbohydrates. If they had high blood glucose levels (greater than $300 \mathrm{mg} / \mathrm{dl}$ ), they had to control their blood glucose level by exercise within 20 to 30 minutes. Pointed out that, all variables relevant to the parameters were measured 2 days before, and 2 days after the study.

Measurement of anthropometric indices: Initially the anthropometric indices included weight, height, and body fat percent (BF \%), body mass index (BMI), waist-hip ratio (WHR) was measured with minimal clothing and no shoes. Body weight and stand height was measured using weight machine Seca type, made in Germany (Seca 714, seca Vogel and Halk Gmbh) with precision $\pm 0 / 1 \mathrm{~kg}$ and height machine Seca type, made in Germany (Seca 714, seca Vogel and Halk Gmbh) with precision $\pm 0 / 1$ centimeters, respectively. BMI was calculated by dividing body weight $(\mathrm{kg})$ by height square (square meters). Moreover, calipers RH.15.9LB model made in Germany [30] was used for measuring the thickness of skinfold with its underlying fat layer by three-point method (assessing skinfolds in triceps, abdomen and suprailiac). Then the sum of skinfolds was implanted in the general equation of Jackson and Pollock for determining BF\% in study population [31]. Participants' WHR was also calculated by taking the waist circumference $(\mathrm{cm})$ dividing by the hip circumference $(\mathrm{cm})$.

Measurement of blood indices: Fasting blood sampl e s were collected in two stages; pre-test and post-test (two days before and two days after completion of 12 weeks of exercise). The sample consisted of $7 \mathrm{ml}$ of antecubital venous blood that was taken between the hours of 7 to $10 \mathrm{am}$ following an overnight fast. The subjects were asked to avoid performing any hard exercise during the 48 hours before both stages of blood sampling. Blood samples were maintained to measure resistin after centrifugation and separation of serum at a temperature of $-80^{\circ} \mathrm{C}$ to analyze with post-test blood samples. Serum resistin level was measured with sandwich immunoassay enzyme method, using an ELISA kit Mediagnost, E 50, made in Germany with a sensitivity 0.012 $\mathrm{ng} / \mathrm{ml}$ and the inter rater and outré rater coefficient variation $6.8 \%$ and $5 \%$ respectively. Values of FBG, low density lipoprotein (LDL), high density lipoprotein (HDL), triglyceride (TG) and total cholesterol (TC) was performed by enzymatic method on a Roche Cobas Integra 400 analyzer. Glycosylated hemoglobin A1c (HbAlc) was measured by electrochemiluminescence method using Elecsys 2010 equipment (Roche Kit). Homeostatic model assessment of insulin resistance (HOMA-IR) was calculated to assess the insulin resistance according to the formula given below [32].

HOMA-IR=fasting glucose $(\mathrm{mmol} / \mathrm{l}) \times$ fasting insulin $(\mu \mathrm{U} / \mathrm{ml}) / 22.5$

Exercise intervention: Participants in the AEX group performed impulse PT300 treadmill walking/running exercise; 3x/week for 12 weeks. Their program included 10 minutes warm-up, exercises with intensity of $40-50 \%$ of HR max for 20 minutes and then cool down periods. Exercises intensity gradually increased with the progress of the training program to $70-80 \%$ of HR max for $45-50 \mathrm{~min}$. In order to determine percentage of target heart rate for each [33] session; HR max of every subject was calculated using the formula; "HR $\max =220$ age'”, then following equation was calculated [34];

Target heart rate $=(50-70) \%$ (HR max-resting heart rate $)+$ resting heart rate

Exercises intensity was controlled using stethoscope Polar (Polar, S810, Kempele, Finland) to ensure compliance activity. To learn the correct exercises; program for resistance exercise participants was begun one day earlier. In their first training session; for each of the exercises one repetition maximum (RM 1) was estimated according to the following formula [35];

Weight $\times\{1+(30 /$ number of reps $)\}=$ RM 1 
Participants in REX group performed 9 power moves as 3 sets with 10 repetitions, rest periods between sets was considered 60-90 seconds. Each resistance session was 1 hour consists of 10 minutes of warming up, 40-45 minutes of main training and 5 minutes of cooling-down. Every two weeks work load (RM 1) was recalculated to observe the principle of over load and increase the intensity, thus the first four weeks, with $40-45 \%$ of RM 1, the second four weeks with $50-55 \%$ of RM 1 and the last four weeks, with $60-65 \%$ of one RM 1 [36]. Resistance training included 4-motion for upper body muscles: bench press, shoulder press, standing cable curl with rope and rope press down and 3 motion for lower body muscles: leg press, leg extension and leg flexion and the two movements for anterior muscles, abdominal and back extension.

Combined training program included all programs of AEX and REX with the same intensity, duration and time. Their program composed two sessions of AEX and one REX session during the first two weeks and within the second two weeks; two sessions of REX training and one AEX training session. The program was repeated intermittently for 12 weeks.

All exercise sessions were performed under the supervision of a physical therapist.

During the study period, the control group was advised to continue their normal daily routines and activities.

Ethical considerations: Our research approved by the ethics committee of Urmia University of Medical Sciences. All of the participants were briefed on the study objectives and related sports activities. Subjects were informed that their participation was voluntary. Consent was obtained from all subjects and emphasized that they could refuse participation or leave the study at any, and thus would not adversely affect treatment or care provided by their endocrinology clinic.

Statistical analyses: All the descriptive data were expressed in terms of mean \pm standard error of the mean (SEM). KolmogorovSmirnov test (KS test) and Levene's test were used for the detection of normal distribution of data and homogeneity of variance, respectively. One-way ANOVA test was used to examine group differences in the various parameters in the base line and two-way ANOVA and Tukey test was used to compare parameter changes between intervention groups. To determine the independent predicator variables of insulin resistance linear regression method was used. All data was analyzed using an SPSS version 21 with statistical significance set at an alpha level of $\leq 0.05$.

\section{Results}

Seven women were excluded from the study subjects ; one subject from the aerobic group because of an illness unrelated to this study, four subjects from resistance and combined groups due to nonparticipation in training program, also two subjects from the control group because they did not participate for the blood sampling test in post-test phase. Finally the results analysis was performed with 33 subjects. The mean age of participants and their BMI were 58.30 \pm 5.28 and $32.10 \pm 3.31$, respectively. The subjects' characteristics did not significantly differ between the groups at the baseline according to one way Anova test $(\mathrm{P}>0.05)$ (Table 1). Table 2 illustrated results of Tukey test to determine differences between groups in mean changes of anthropometric and biochemical variables of four groups, before and after the intervention.
The results of two-way Anova test followed by Tukey test shown that; Among the anthropometric variables; While the mean changes of weight had significant difference between AEX and REX groups $(\mathrm{p}=0.04)$, the effect of AEX group $(-2.14 \pm 0.32)$ in weight loss was more than REX group $(-2.08 \pm 0.99)$. The mean changes of $B F \%$ had significant difference between the aerobic -control groups $(\mathrm{p}=0.01)$, AEX - REX $(\mathrm{p}<0.001)$ and AEX - combined groups $(\mathrm{p}<0.001)$. The effect of combined group in decreasing BF\% (-2.5 \pm 0.42$)$ was more than AEX group $(-2.07 \pm 0.56)$ and the effect of AEX group was more than control group $(0.95 \pm 0.52)$ and REX group $(-0.35 \pm 0.93)$. Whereas the mean changes of WHR had significant difference between AEX combined groups ( $\mathrm{p}=0.01)$, the effect of AEX group $(-0.06 \pm 0.008)$ was more than the combined group $(0.01 \pm 0.03)$ (Table 2$)$.

Also, among the glycemic indices; the mean difference of insulin changes was significant between AEX and REX groups $(p=0.01)$. The effect of REX for insulin reduction $(-0.70 \pm 0.88)$ was more than AEX group $(-0.04 \pm 0.81)$. The mean difference of IR changes was significant between AEX and REX groups ( $\mathrm{p}<0.001)$ and REX - combined groups $(p=0.02)$. The effect of the REX group $(-4.07 \pm 1.23)$ in IR reduction was more than the AEX group $(-1.94 \pm 1.16)$ and the combined group $(-1.88 \pm 0.79)$ (Table 2).

Among the lipid profile parameters; while the mean difference of LDL changes was significant between REX - combined groups $(\mathrm{p}=0.04)$, the effect of the combined group $(-13.28 \pm 2.48)$ in reducing LDL was more than the REX group $(-11.84 \pm 6.76)$. The mean difference of TC changes was significant between AEX - REX groups ( $\mathrm{p}=0.04)$ and REX -combined groups $(p=0.04)$ whereas the effect of the REX group $(-42.55 \pm 10.73)$ was more than AEX $(-34.44 \pm 5.26)$ and combined groups $(-36.00 \pm 3.54)$ in TC reduction (Table 2).

Moreover, about the mean changes of PRL; a significant difference between AEX -control groups ( $\mathrm{p}=0.03)$ and control-combined groups $(p=0.03)$ was observed. The effect of AEX group $(9.35 \pm 0.93)$ and combined group $(3.50 \pm 1.43)$ was more than control group $(0.23 \pm$ 0.20 ) for increasing PRL (Table 2).

The value of $\mathrm{R}$ square in multiple regressions; for insulin resistance as dependent variable in both pre-and post-test was 0.983 and 0.985 respectively. The regression model in both pre-and posttest is as follows:

Pre-test: $\mathrm{IR}=-9.20+0.04$ Weight+0.05 FBG+1.05 Insulin+0.009 TG+0.01 LDL

Post-test: IR $=-3.30+0.02$ Weight+2.14 WHR+0.31 HbA1c+0.07 FBG+0.93 Insulin

So that; with 1- unit increase in the amount of body weight, FBG insulin, TG and LDL in the pretest phase, if all other variables remain constant, a change order of $0.04,0.05,1.05,0.009,0.01$ units was predict in IR. In post-test phase also one unit change of body weight, WHR HbA1c, FBG and insulin, if all other variables remain constant, predicts a change order of, 0.02, 2.14, 0.31, 0.07, 0.93 units in IR.

\section{Discussion}

Physical activity improves homeostasis, energy balance and various types of regulatory responses [37]. Indeed, physiological adaptations such as hormonal and metabolic responses are under the influence of different types of exercises. These efficacies are different based on the exercise type [38]. So, we aimed to compare changes in PRL, lipid profile and glycemic indices in obese postmenopausal women with DMT2 following the implementation of 12 weeks of AEX, REX and combination exercises and also to provide regression models for IR in 
Citation: Tofighi A, Samadian Z, Mahdizadeh A (2016) Blood Levels of Resistin, Glycemic Indices and Lipid Profile in Women with Type 2 Diabetes. J Diabetes Metab 7: 702. doi: 10.4172/2155-6156.1000702

Page 4 of 7

\begin{tabular}{|c|c|c|c|c|c|c|}
\hline \multicolumn{2}{|l|}{ Variable } & \multirow{2}{*}{$\begin{array}{c}\begin{array}{c}\text { Aerobic } \\
\text { (n:9) }\end{array} \\
58.33 \pm 1.88\end{array}$} & \multirow{2}{*}{$\begin{array}{c}\begin{array}{c}\text { Resistance } \\
\text { (n:8) }\end{array} \\
57.12 \pm 1.79\end{array}$} & \multirow{2}{*}{$\begin{array}{c}\begin{array}{c}\text { Combined } \\
\text { (n:8) }\end{array} \\
56.50 \pm 1.87\end{array}$} & \multirow{2}{*}{\begin{tabular}{|c|c}
$\begin{array}{c}\text { Control } \\
(\mathbf{n}: 8)\end{array}$ \\
$61.25 \pm 177$
\end{tabular}} & \multirow{2}{*}{$\begin{array}{c}{ }^{*} \mathbf{p} \text {-value } \\
0.29\end{array}$} \\
\hline A & pre & & & & & \\
\hline Age (year) & post & - & - & - & - & - \\
\hline \multirow{2}{*}{ Height (cm) } & pre & $154.61 \pm 1.57$ & $158.93 \pm 1.74$ & $158.62 \pm 0.65$ & $156.56 \pm 2.69$ & 0.30 \\
\hline & post & - & - & - & - & - \\
\hline \multirow{2}{*}{$\begin{array}{l}\text { Time of diabetes } \\
\text { diagnosis (year) }\end{array}$} & pre & $4.88 \pm 1.07$ & $10.12 \pm 1.27$ & $8.00 \pm 1.46$ & $7.25 \pm 1.34$ & 0.06 \\
\hline & post & - & - & - & - & - \\
\hline \multirow{2}{*}{ Weight (kg) } & pre & $75.66 \pm 3.67$ & $83.56 \pm 3.06$ & $79.68 \pm 2.17$ & $77.62 \pm 3.00$ & 0.321 \\
\hline & post & $73.52 \pm 3.48$ & $81.58 \pm 2.40$ & $76.27 \pm 2.27$ & $77.95 \pm 3.11$ & - \\
\hline \multirow{2}{*}{ BMI (kg/m²) } & pre & $31.73 \pm 1.60$ & $33.25 \pm 1.19$ & $31.77 \pm 0.89$ & $31.71 \pm 0.69$ & 0.75 \\
\hline & post & $30.84 \pm 1.53$ & $32.55 \pm 0.98$ & $30.40 \pm 0.89$ & $31.84 \pm 0.74$ & - \\
\hline \multirow{2}{*}{ BF (\%) } & pre & $36.33 \pm 1.79$ & $43.08 \pm 1.14$ & $43.81 \pm 0.93$ & $39.48 \pm 1.86$ & 0.55 \\
\hline & post & $34.25 \pm 1.78$ & $42.95 \pm 1.19$ & $41.26 \pm 1.09$ & $40.43 \pm 1.42$ & - \\
\hline \multirow{2}{*}{ WHR } & pre & $0.89 \pm 0.02$ & $0.87 \pm 0.01$ & $0.92 \pm 0.02$ & $0.87 \pm 0.02$ & 0.44 \\
\hline & post & $0.82 \pm 0.02$ & $0.88 \pm 0.01$ & $0.94 \pm 0.02$ & $0.88 \pm 0.01$ & - \\
\hline \multirow{2}{*}{ HbA1c (\%) } & pre & $7.94 \pm 0.40$ & $8.80 \pm 0.63$ & $8.07 \pm 0.50$ & $7.63 \pm 0.26$ & 0.36 \\
\hline & Post & $7.03 \pm 0.43$ & $7.73 \pm 0.48$ & $6.70 \pm 0.29$ & $7.57 \pm 0.31$ & - \\
\hline \multirow{2}{*}{ FBG (mg/dl) } & pre & $144.88 \pm 13.19$ & $178.75 \pm 19.13$ & $155.87 \pm 11.12$ & $136.12 \pm 9.63$ & 0.17 \\
\hline & post & $105.55 \pm 7.73$ & $124.12 \pm 14.86$ & $117.25 \pm 6.01$ & $146.12 \pm 4.32$ & - \\
\hline \multirow{2}{*}{ Insulin $(\mu \mathrm{lU} / \mathrm{ml})$} & pre & $6.09 \pm 0.80$ & $9.09 \pm 0.70$ & $7.04 \pm 1.18$ & $7.86 \pm 0.67$ & 0.10 \\
\hline & Post & $6.04 \pm 0.64$ & $8.09 \pm 0.64$ & $6.82 \pm 0.95$ & $6.88 \pm 0.67$ & - \\
\hline \multirow{2}{*}{ IR (HOMA-IR) } & pre & $7.00 \pm 1.12$ & $12.65 \pm 1.33$ & $8.44 \pm 1.21$ & $8.48 \pm 0.95$ & 0.12 \\
\hline & post & $5.06 \pm 0.64$ & $8.02 \pm 1.23$ & $6.28 \pm 0.77$ & $8.00 \pm 0.73$ & - \\
\hline \multirow{2}{*}{ TG (mg/dl) } & pre & $166.88 \pm 22.76$ & $212.75 \pm 30.66$ & $138.12 \pm 24.87$ & $166.50 \pm 24.77$ & 0.26 \\
\hline & post & $111.11 \pm 10.87$ & $146.00 \pm 24.58$ & $102.00 \pm 16.93$ & $168.00 \pm 24.69$ & \\
\hline \multirow{2}{*}{ HDL (mg/dl) } & pre & $52.66 \pm 2.81$ & $52.87 \pm 5.19$ & $52.47 \pm 2.11$ & $50.41 \pm 3.24$ & 0.95 \\
\hline & post & $60.43 \pm 2.12$ & $53.91 \pm 3.92$ & $59.95 \pm 1.21$ & $49.60 \pm 2.61$ & - \\
\hline \multirow{2}{*}{ LDL (mg/dl) } & pre & $110.78 \pm 4.51$ & $126.87 \pm 12.00$ & $101.58 \pm 12.57$ & $111.25 \pm 9.79$ & 0.37 \\
\hline & post & $91.24 \pm 3.92$ & $114.46 \pm 10.36$ & $87.55 \pm 11.22$ & $117.71 \pm 9.63$ & - \\
\hline \multirow{2}{*}{ TC (mg/dl) } & pre & $180.77 \pm 3.19$ & $214.62 \pm 14.17$ & $180.75 \pm 16.99$ & $190.00 \pm 12.05$ & 0.19 \\
\hline & post & $146.33 \pm 3.05$ & $171.12 \pm 7.89$ & $144.62 \pm 13.91$ & $189.50 \pm 9.61$ & - \\
\hline \multirow{2}{*}{ Resistin (ng/ml) } & pre & $11.88 \pm 1.30$ & $12.94 \pm 1.04$ & $15.06 \pm 0.93$ & $13.22 \pm 0.54$ & 0.19 \\
\hline & post & $21.24 \pm 1.64$ & $18.70 \pm 1.43$ & $18.13 \pm 0.99$ & $13.45 \pm 0.66$ & - \\
\hline
\end{tabular}

Data are shown as mean \pm standard error of the mean (Mean \pm SEM). Difference were not seen between groups at baseline levels of all variables (one way Anova test significant level $\left(p \geq 0 / 05^{*}\right)$

Table 1: Anthropometric and biochemical characteristics of subjects at different stages (pre-test and post-test).

\begin{tabular}{|c|c|c|c|c|c|c|}
\hline \multirow{2}{*}{$\begin{array}{c}\text { Groups } \\
\text { Variable }\end{array}$} & \multicolumn{3}{|c|}{ Control } & \multicolumn{2}{|c|}{ aerobic } & \multirow{2}{*}{$\begin{array}{l}\text { Resistance } \\
\text { Combined }\end{array}$} \\
\hline & aerobic & Resistance & Combined & Resistance & combined & \\
\hline Weight (kg) & 0.70 & 0.40 & 1.00 & $0.04^{*}$ & 0.66 & 0.43 \\
\hline BMI $\left(\mathbf{k g} / \mathrm{m}^{2}\right)$ & 0.97 & 0.77 & 0.93 & 0.49 & 0.99 & 0.41 \\
\hline BF (\%) & $0.01^{*}$ & 0.18 & 0.32 & $\square 0.001^{*}$ & $\square .001^{*}$ & 0.98 \\
\hline WHR & 0.85 & 1.00 & 0.10 & 0.84 & $0.01^{*}$ & 0.10 \\
\hline HbA1c (\%) & 0.99 & 0.42 & 0.96 & 0.27 & 0.99 & 0.19 \\
\hline FBG (mg/dl) & 0.51 & 0.81 & 0.98 & 0.11 & 0.75 & 0.59 \\
\hline Insulin $(\mu \mathrm{lU} / \mathrm{ml})$ & 0.35 & 0.44 & 0.94 & $0.01^{*}$ & 0.69 & 0.18 \\
\hline IR (HOMA-IR) & 0.14 & 0.19 & 0.83 & $\square 0.001^{*}$ & 0.56 & $0.02^{*}$ \\
\hline TG (mg/dl) & 0.59 & 0.95 & 0.19 & 0.29 & 0.83 & 0.06 \\
\hline HDL (mg/dl) & 0.15 & 0.70 & 0.20 & 0.73 & 1.00 & 0.80 \\
\hline LDL (mg/dl) & 0.48 & 0.91 & 0.17 & 0.16 & 0.90 & $0.04^{*}$ \\
\hline $\mathrm{TC}$ (mg/dl) & 0.08 & 0.99 & 0.07 & $0.04^{*}$ & 1.00 & $0.04^{*}$ \\
\hline Resistin (ng/ml) & $0.03^{*}$ & 0.16 & $0.03^{*}$ & 0.91 & 1.00 & 0.91 \\
\hline
\end{tabular}

*The mean difference is significant at $\mathrm{p} \square 0.05$.

Table 2: Results of Tukey test to determine differences between groups in mean changes of anthropometric and biochemical variables.

two phases of our research; pre-test and post-test. It should be noted that, our inclusion and exclusion criteria and also design exercise protocol differ from other studies in this field (Table 3).

Comparing mean changes of anthropometric indices; determined that the result of AEX in weight loss was more than REX. While the effect of combined group in decreasing $\mathrm{BF} \%$ was more than AEX group, but the consequence of AEX was more than the combined group for reducing WHR. Hereon, the more effect of combined exercise beside AEX as compared to REX may be display the compensatory mechanism 


\begin{tabular}{|c|c|c|c|c|c|c|c|c|}
\hline Studies & Duration, Intensity & Type of exercise & $\begin{array}{l}\text { Sample } \\
\text { Size }\end{array}$ & $\begin{array}{l}\text { Type of } \\
\text { Subjects }\end{array}$ & Sex & $\begin{array}{c}\text { Age } \\
\text { (years) }\end{array}$ & $\begin{array}{c}\text { Diet } \\
\text { intervention }\end{array}$ & Results \\
\hline $\begin{array}{l}\text { Giannopoulou } \\
\text { et al. [22] }\end{array}$ & $\begin{array}{c}14 \text { weeks }(3 \text { to } 4 x / \text { week for } 60 \mathrm{~min} \\
\text { at } 65 \%-70 \% \mathrm{VO}_{2} \text { peak) }\end{array}$ & aerobic & $\begin{array}{c}33 \\
\text { subjects }\end{array}$ & Human & Female & $50-70$ & yes & $\begin{array}{c}\text { No significant change of } \\
\text { resistin }\end{array}$ \\
\hline $\begin{array}{c}\text { Jones et al. } \\
\text { [23] }\end{array}$ & $\begin{array}{c}32 \text { weeks( } 3 \text { days/week, for } 60 \\
\left.\min , 60 \%-85 \% \mathrm{VO}_{2} \max \right)\end{array}$ & aerobic & $\begin{array}{c}12 \\
\text { subjects }\end{array}$ & Human & Female/Male & $15.3 \pm 0.5$ & No & Resistin decreased \\
\hline $\begin{array}{l}\text { Prestes et al. } \\
\text { [24] }\end{array}$ & $\begin{array}{c}16 \text { weeks(two weekly sessions } \\
\text { of three sets of } 6-14 \text { repetition } \\
\text { maximum) }\end{array}$ & resistance & $\begin{array}{c}35 \\
\text { subjects }\end{array}$ & Human & Female & mean age 63.18 & No & Resistin decreased \\
\hline $\begin{array}{l}\text { Jorg et al. } \\
\quad[25]\end{array}$ & $\begin{array}{c}12 \text { weeks(3 days/week } 60 \\
\text { minutes) }\end{array}$ & $\begin{array}{l}\text { Aerobic(cycling) } \\
\text { Resistance } \\
\text { Combined(Aerobic- } \\
\text { Resistance) }\end{array}$ & $\begin{array}{c}48 \\
\text { subjects }\end{array}$ & Human & Female/Male & $53.9 \pm 9.9$ & No & $\begin{array}{c}\text { No significant change of } \\
\text { resistin }\end{array}$ \\
\hline
\end{tabular}

Table 3: Comparison of this study with some other published papers in this field.

of AEX in combined training. Nevertheless; the beneficial effects of all types of training on anthropometric indices were mentioned in studies $[39,40]$. Our results related to weight loss and BF\% were in opposition to the results from Yavari et al. [41] but consistent with the results from Sigal et al. [38] About comparing the WHR changes between groups, the results of this study was different from Jorg et al. study [25] and consistent with the results from Sigal et al. that shown the high impact of AEX for WHR reduction [38].

The consequence of the REX in insulin and IR reduction was more than the AEX group. This finding is inconsistent with Jorg et al. who reported no significant differences was observed about these two variables [25], while is consistent with the study from Al-Kader et al. [42] The greater impact REX on changes in insulin and IR can be justified by the effect of this exercise on muscle mass. The insulin sensitivity is present in skeletal muscle; therefore, increasing muscle mass by REX can be effective in glycemic control and reducing IR [17].

In this study, no significant differences were observed in the mean changes of HbA1c and FBG between groups. This result is inconsistent with study results by Reid et al. who reported the superiority of REX to AEX in $\mathrm{HbA} 1 \mathrm{c}$ reduction [43] and reported from Sigal et al. who stated the greater effect of AEX on HbAlc decrease [38]. Sigal et al. and Arora et al. reported that, exercise were more effective among patients with higher baseline Hbalc compared with lower HbAlc [38,44]. Moreover, our results about FBG was inconsistent with Shenoy et al. that showed REX are more effective in improving FBG compared to AEX [45].

Among lipid profile index; significant difference were observed in the mean changes of LDL and TC. Our findings revealed that, the effect of the combined group was more than REX for LDL reducing. In addition; the effect of REX was more than AEX and combined groups in TC decreasing. These results were inconsistent with Sigal et al. study [38] and one meta-analysis study [46] that did not find any change for these variables following exercises. While reducing TC in our study was consistent with a study that shown a greater efficacy of REX in terms of improving levels of TC and LDL among Hindi population [44]. The possible mechanisms for interpretation of improving the lipid profile can be the increased Peroxisome Proliferator-activated Receptor gamma (PPAR $\gamma$ ), PPAR $\gamma$ coactivator-1alpha (PGC-1 $\alpha$ ) as a key regulator of energy metabolism and messenger ribonucleic acid (mRNA) expression in adipose and muscle tissue after exercise [47].

The main finding of this study was that; the mean changes of resistin were significant between the control- AEX groups and controlcombined groups. So that AEX and combined groups have shown greater effect on the PRL increasing as compared to control group. Even though one study was reported that no significant difference were observed in the mean changes of PRL among the three exercises groups [25]. But consistent with our study, PRL increasing was reported due to exercise in the studies by Camera et al. [48 ] and Monzillo et al. [49]. On the other hand, PRL reduction were stated in the two survey; one of them evaluated the effects of 12 -months physical activity in patients with DMT2 [50] and the other assessed the effects of 16 weeks of resistance training in older postmenopausal women [24]. Notably, increased resistin levels has been reported in study on obese mice [51] and also it should be noted that; resistin levels are described higher in men than in women [52].

This issue is noteworthy that; resistin in addition to adipose tissue is produced in blood mononuclear cells and leukocytes in human body $[11,49]$. It is likely; these cells play a role for increasing resistin gene expression in response to exercise stimulation. In confirmed of this possibility, some studies have expressed that increased resistin levels due to exercises associated with reducing the anthropometric indices and pro-inflammatory cytokines, including IL-1, IL-6, and TNF- $\alpha$. While these cytokines stimulate resistin gene expression in blood mononuclear cells [53]. The most important mechanism to explain increased resistin after exercise training is its role in defending the body against oxidation, as resistin acts as an antioxidant in response to inflammatory stimuli [54].

According to regression model in this study; there was no significant correlation in IR with increased resistin. This finding is in consistent with the study by Leehey et al. [26] and inconsistent with Coello et al. study [55]. Although; resistin known as a hormone that potentially links obesity to diabetes $[56,57]$.

\section{Limitation of the Study}

The present study was a quasi-experimental research among DMT2 patients. Control factors such as genetic factors or other factors independent to the obesity and diabetes were out of the researchers' responsibility, while these factors can affect the study results. The low number of subjects in the different study groups can be also considered as a limitation of this study that is effective in our findings.

\section{Conclusion}

All three types of exercises- AEX, REX and combinatorial - through different mechanisms have beneficial effects in patients with DMT2 in terms of weight loss, BF \% and FBG; however, combined exercise can apply multiple effects due to compensatory mechanisms of AEX and REX on some parameters. This study did not confirm the idea that adipocytokines secreted by adipose tissue like resistin has effect on insulin resistance since according to the regression results, resistin may not be the link between obesity and IR in DMT2 patients. It also seems that an increasing in PRL cannot induce IR. However, further research is recommended to determine the association between resistin and IR in humans and also the effects of exercise on the levels of this adipokines among patients with DMT2. 
Citation: Tofighi A, Samadian Z, Mahdizadeh A (2016) Blood Levels of Resistin, Glycemic Indices and Lipid Profile in Women with Type 2 Diabetes. J Diabetes Metab 7: 702. doi: 10.4172/2155-6156.1000702

Page 6 of 7

\section{References}

1. Rajput BS (2011) Influence of yoga practices and swimming programme on insulin level of diabetic patients. IJAR 3: 303-304.

2. Genco RJ, Grossi SG, Ho A, Nishimura F, Murayama Y (2005) A proposed model linking inflammation to obesity, diabetes, and periodontal infections. J Periodontol 76: 2075-2084

3. Norris LE, Collene AL, Asp ML, Hsu JC, Liu LF, et al. (2009) Comparison of dietary conjugated linoleic acid with safflower oil on body composition in obese postmenopausal women with type 2 diabetes mellitus. Am J Clin Nutr 90: 468476 .

4. Golbidi S, Laher I (2014) Exercise induced adipokine changes and the metabolic syndrome. J Diabetes Res 2014: 726861.

5. Sánchez-Solana B, Laborda J, Baladrón V (2011) Mouse resistin modulates adipogenesis and glucose uptake in 3T3- L1 preadipocytes through the ROR1 receptor. Mol Endo crinol 26: 110-127.

6. Freemantle N, Holmes J, Hockey A, Kumar S (2008) How strong is the association between abdominal obesity and the incidence of type 2 diabetes? Int J Clin Pract 62: 1391-1396.

7. Gastaldelli A (2008) Abdominal fat: does it predict the development of type 2 diabetes? Am J Clin Nutr 87: 1118-1119.

8. Huang T, Qi Q, Zheng Y, Ley HS, Manson EJ, et al. (2015) Genetic Predisposition to Central Obesity and Risk of Type 2 Diabetes: Two Independent Cohort Studies. Diabetes Care 10: 3084.

9. Krishnan S, Rosenberg L, Djoussé L, Cupples LA, Palmer JR (2007) Overall and central obesity and risk of type 2 diabetes in U.S. black women. Obesity (Silver Spring) 15: 1860-1866.

10. Devanoorkar A, Kathariya R, Guttiganur N, Gopalakrishnan D, Bagchi P (2014) Resistin: A Potential Biomarker for Periodontitis Influenced Diabetes Mellitus and Diabetes Induced Periodontitis. Disease Markers 22: 12-23.

11. Qiu W, Chen N, Zhang Q, Zhuo L, Wang X, et al. (2014) Resistin increases platelet P-selectin levels via p38 MAPK signal pathway. Diab Vasc Dis Res 11: $121-124$.

12. Bajaj M, Suraamornkul S, Hardies LJ, Pratipanawatr T, DeFronzo RA (2004) Plasma resistin concentration, hepatic fat content, and hepatic and peripheral insulin resistance in pioglitazone-treated type II diabetic patients. Int $\mathrm{J}$ Obes Relat Metab Disord 28: 783-789.

13. Jamaluddin MS, Weakley SM, Yao Q, Chen C (2012) Resistin: functional roles and therapeutic considerations for cardiovascular disease. $\mathrm{Br} \mathrm{J}$ Pharmaco 165: 622-632.

14. Zhou L, Li Y, Xia T, Feng S, Chen X, et al. (2006) Resistin overexpression impaired glucose tolerance in hepatocytes. Eur Cytokine Netw 17: 189-195.

15. Utzschneider KM, Carr DB, Tong J, Wallace TM, Hull RL, et al. (2005) Resistin is not associated with insulin sensitivity or the metabolic syndrome in humans. Diabetologia 48: 2330-2333.

16. Al- Daghvi U, Chetty R, Mc Ternan P, Al- Robean K, Al Attas O, et al. (2004) Serum resistin is associated with $\mathrm{C}$ - reactive protein and LDL-cholesterol in type 2 diabetes and coronary artery disease in a Saudi population. Cardiovascular Diabetology 4: 10.

17. Marcus RL, Smith S, Morrell G, Addison O, Dibble LE, et al. (2008) Comparison of combined aerobic and high-force eccentric resistance exercise with aerobic exercise only for people with type 2 diabetes mellitus. PhysTher 88: 1345-1354.

18. Bacchi E, Negri C, Zanolin ME, Milanese C, Faccioli N, et al. (2012) Metabolic effects of aerobic training and resistance training in type 2 diabetic subjects: a randomized controlled trial (the RAED2 study). Diabetes Care 35: 676-682.

19. Kim Y, Park H (2013) Does Regular Exercise without Weight Loss Reduce Insulin Resistance in Children and Adolescents? Int J Endocrinol 13: 402592.

20. Turcotte LP, Fisher JS (2008) Skeletal muscle insulin resistance: roles of fatty acid metabolism and exercise. Phys Ther 88: 1279-1296.

21. Eves ND, Plotnikoff RC (2006) Resistance training and type 2 diabetes: Considerations for implementation at the population level. Diabetes Care 29: 1933-1941.

22. Giannopoulou I, Fernhall B, Carhart R, Weinstock R, Weinstock RS, et al. (2005) Effects of diet and/ or exercise on the adipocytokine and inflammatory cytokine levels of postmenopausal women with type 2 diabetes. Metabolism clinical and Experimental 54: 866-875.

23. Jones TE, Basilio JL, Brophy PM, McCammon MR, Hickner RC (2009) Long term exercise training in overweight adolescents improves plasma peptide $Y Y$ and resistin. Obesity (Silver Spring) 17: 1189-1195.

24. Prestes J, Shiguemoto G, Botero JP, Frollini A, Dias R, et al. (2009) Effects of resistance training on resistin, leptin, cytokines, and muscle force in elderly post-menopausal women. J Sports Sci 27: 1607-1615

25. Jorge M, Olireira V, Resende N, ParaisoL, Calixto A, et al. (2011) The effects of aerobic, resistance and combined exercise on metabolic control, inflammatory markers, adipocytokines and muscle insulin signaling in patients with type 2 diabetes mellitus. Metabolism clinical and experimental 60: 1244-1252.

26. Leehey DJ, Moinuddin I, Bast JP, Qureshi S, Jelinek CS, et al. (2009) Aerobic exercise in obese diabetic patients with chronic kidney disease: a randomized and controlled pilot study. Cardiovasc Diabetol 8: 62

27. Slentz CA, Houmard JA, Kraus WE (2009) Exercise, abdominal obesity skeletal muscle, and metabolic risk: evidence for a dose response. Obesity (Silver Spring) 17: S27-33.

28. Alberti KG, Zimmet PZ (1998) Definition, diagnosis and classification of diabetes mellitus and its complications.Part I: Diagnosis and classification of diabetes mellitus provisional report of a WHO consultation. Diabet Med 15 539-553.

29. Thomas S, Reading J, Shephard RJ (1992) Revision of the Physical Activity Readiness Questionnaire (PAR-Q). Can J Sport Sci 17: 338-345.

30. Milce B, Judy P, Heather MT, Kraemer W, Fleck S (2007) [BOOK] Optimizing strength training designing nonlinear periodization workouts ( $1^{\text {ste }}$ edn). united states: human kinetics

31. Jackson AS, Pollock ML, Ward A (1980) Generalized equations for predicting body density of women. Med Sci Sports Exerc 12: 175-181.

32. Matthews DR, Hosker JP, Rudenski AS, Naylor BA, Turner RC, et al. (1985) Homeostasis model assessment: insulin resistance and $B$-cell function from fasting plasma glucose and insulin concentrations in man. Diabeto Logia 28 412-419.

33. Robergs RA, Landwehr R (2002) The surprising history of the 'HR max $=220$ age' equation. $J$ ExercPhysiol online 5: 1-16

34. Houmard JA, Kraus WE (2010) American Heart Association's Recommendations for Physical Activity in Adults 12: 52-60.

35. Maud PJ, Foster C (2010) Physiological assessment of human fitness. Champaign: human kinetics 2006: 119-150.

36. Kraemer WJ, Ratamess NA (2004) Fundamentals of resistance training: progression and exercise prescription. Med Sci Sports Exerc 36: 674-688.

37. Roupas ND, Mamali I, Maragkos S, Leonidou L, Armeni AK, et al. (2013) The effect of prolonged aerobic exercise on serum adipokine levels during an ultramarathon endurance race. Hormones (Athens) 12: 275-282.

38. Sigal RJ, Kenny GP, Boulé NG, Wells GA, Prud'homme D, et al. (2007) Effects of aerobic training, resistance training, or both on glycemic control in type 2 diabetes: a randomized trial. Ann Intern Med 147: 357-369.

39. Marwic TH, Hordem MD, Miller T, Chyun DA, Bertoni AG, et al. (2009) Exercise training for type 2 diabetes mellitus: impact on cardiovascular risk: a scientific statement from the American heart association. Circulation 119: 3244-3262.

40. Menezes-Cabral RL, Silva-Dantas PM, Montenegro-Neto AN, Knackfuss Ml (2009) Effects of different types of training and life styles on anthropometric and cardio circulatory markers in aging. Rev salud pública 11: 359-69.

41. Yavari A, Najafipoor F, Aliasgarzadeh A, Niafar M, Mobasseri M (2012) Effect of aerobic exercise, resistance training or combined training on glycemic control and cardiovascular risk factors in patient with type 2 diabetes. Biol Sport 29: 135-143

42. Shehab M, Abd El-Kader (2011) Aerobic versus resistance exercise training in modulation of insulin resistance, adipocytokines and inflammatory cytokine levels in obese type 2 diabetic patients. J Adv res 2: 179-183.

43. Reid RD, Tolloch HE, Sigal RJ, Kenny GP, Fortier M, et al. (2010) Effects of aerobic exercise, resistance exercise or bithorn patients - reported health Status and well- being in TZDM mellitus: randomized trial. Diabetologia 53 632-640. 
Citation: Tofighi A, Samadian Z, Mahdizadeh A (2016) Blood Levels of Resistin, Glycemic Indices and Lipid Profile in Women with Type 2 Diabetes. J Diabetes Metab 7: 702. doi: 10.4172/2155-6156.1000702

44. Arora E, Shenoy S, Sandhu JS (2009) Effects of resistance training on metabolic profile of adults with type 2 diabetes. Indian J Med Res 129: 515-519.

45. Shenoy S, Arova E, Jaspal S (2009) Effects of progressive resistance training and aerobic exercise onT2DM in Indian population. Int J Diabetes Metab 17 27-30.

46. Kraus WE, Houmard JA, Duscha BD, Knetzger KJ, Wharton MB, et al. (2002) Effects of the amount and intensity of exercise on plasma lipoproteins. $\mathrm{N}$ Engl J Med 347: 1483-1492.

47. Ruschke, Fish bein L, Dietrich A, Kloting N, Tonies A, et al. (2010) Gene expression of PPARgamma and PGC- 1 alpha in human mental and subcutaneous adipose tissues is related to insulin resistance markers and mediates beneficial effects of physical training. Eur J Endocrinol 162: 515-523.

48. Camera DM, Anderson MJ, Hawley JA, Carey AL (2010) Short-term endurance training does not alter the oxidative capacity of human subcutaneous adipose tissue. Eur J ApplPhysiol 109: 307- 316.

49. Monzillo LU, Hamdy O, Horton ES, Ledbury S, Mullooly C, et al. (2003) Effect of lifestyle modification on adipokine levels in obese subjects with insulin resistance. Obes Res 11: 1048-1054.

50. Balducci S, Zanuso S, Nicolucci A, Fernando F, Cavallo S, et al. (2010) Antiinflammatory effect of exercise training in subjects with type 2 diabetes and the metabolic syndrome is dependent on exercise modalities and independent of weight loss. Nutr Metab Cardiovasc Dis 20: 608-617.
51. Nieva-Vazquez A, Pérez-Fuentes R, Enrique Torres-Rasgado E, López-López JG, Romero JR (2014) Serum Resistin Levels Are Associated with Adiposity and Insulin Sensitivity in Obese Hispanic Subjects. Metab Syndr Relat Disord 12: $143-148$.

52. Kadoglou NP, Perrea D, lliadis F, Angelopoulou N, Liapis C, et al. (2007) Exercise reduces resistin and inflammatory cytokines in patients with type 2 diabetes. Diabetes Care 30: 719-721.

53. Tsiotra PC, Boutati E, Dimitriadis G, Raptis SA (2013) High insulin and leptin increase resistin and inflammatory cytokine production from human mononuclear cells. BioMed research international 20: 12-19.

54. Bo S, Gambino R, Pagani A, Guidi S, Gentile L, et al. (2005) Relationships between human serum resistin, inflammatory markers and insulin resistance. Int J Obes (Lond) 29:1315-1320.

55. Coello D, Leon A, Gonzalez D, Hernandez A, Perez MC, et al. (2008) Inverse association between serum resistin and insulin resistance in humans. Diabetes research and clinical practice 82: 256- 261.

56. Steppan CM, Bailey ST, Bhat S, Brown EJ, Banerjee RR, et al. (2001) The hormone resistin links obesity to diabetes. Nature 409: 307-312.

57. Kusminski CM, McTernan PG, Kumar S (2005) Role of resistin in obesity, insulin resistance and Type II diabetes. Clin Sci (Lond) 109: 243-256. 